\title{
Potential geographical distribution and environmental explanations of rare and endangered plant species through combined modelling: A case study of Northwest Yunnan, China
}

\author{
Pengcheng $\mathrm{Ye}^{1}$, Guangfu Zhang ${ }^{2}$, Xiao Zhao ${ }^{2}$, Hui Chen ${ }^{2}$, Qin $\mathrm{Si}^{2}$, and Jianyong $\mathrm{Wu}^{1}$ \\ ${ }^{1}$ Nanjing Institute of Environmental Sciences \\ ${ }^{2}$ Affiliation not available
}

December 7, 2020

\begin{abstract}
In recent decades, due to the effect of climate change and the interference of human activities, the species habitat index fallen $2 \%$. Studying the geographical distribution pattern and predicting the potential geographical distribution of species are of great significance for developing scientific and effective biodiversity conservation strategies. The purpose of this research is to predict the potential geographical distribution of 25 rare and endangered plant species in Northwest Yunnan, China on the grid map with a resolution of $0.05^{\circ} \times 0.05^{\circ}$ and analyze the explanation capabilities of various environmental factors on the potential geographical distribution patterns of these species, and explore the main restrictive environmental factors. Initially, we employed the ecological niche model MaxEnt to predict the potential geographical distribution of target species. Following that, we overlaid the potential geographical distribution of each species, and we obtained the potential geographical distribution pattern of species richness on the spatial scale of the ecological niche model with a resolution of $0.05^{\circ} \times 0.05^{\circ}$. Ultimately, we also adopted geographically weighted regression (GWR) model to investigate the explanation capabilities of various environmental parameters on the potential distribution patterns. The results showed that the average AUC value of each species was between 0.80 and 1.00, which indicated that the simulation precision of the MaxEnt model for each species was good or excellent. Besides, the potential distribution areas of these species were between $826.33 \mathrm{~km} 2$ and 44,963.53 km2. In addition, the average contribution values of the annual precipitation (Bio12), precipitation of coldest quarter (Bio19) and population density (Pop) were $25.92 \%, 15.86 \%$ and $17.95 \%$, respectively. Moreover, the goodness of fit R2 and AIC value of the water model were 0.88 and 7,703.82, respectively, which indicated the water factor largely influenced the potential distribution of these species. The results of this study would be helpful for implementing long-term conservation and reintroduction for these species.
\end{abstract}

Potential geographical distribution andenvironmental explanations of rare and endangered plant species through combined modelling: A case study of Northwest Yunnan, China

\section{Pengcheng Ye ${ }^{1,2}$, Guangfu Zhang ${ }^{2}$, Xiao Zhao ${ }^{1}$, Hui Chen ${ }^{1}$, Qin Si ${ }^{1}$, Jianyong Wu}

1

${ }^{1}$ Nanjing Institute of Environmental Science, Ministry of Ecology and Environment of the People's Republic of China, Nanjing, China

2 Jiangsu Key Laboratory of Biodiversity and Biotechnology, School of Life Sciences, Nanjing Normal University, Nanjing, China 


\begin{abstract}
In recent decades, due to the effect of climate change and the interference of human activities, the species habitat index fallen 2\%. Studying the geographical distribution pattern and predicting the potential geographical distribution of species are of great significance for developing scientific and effective biodiversity conservation strategies. The purpose of this research is to predict the potential geographical distribution of 25 rare and endangered plant species in Northwest Yunnan, China on the grid map with a resolution of $0.05^{\circ}$ $\times 0.05^{\circ}$ and analyze the explanation capabilities of various environmental factors on the potential geographical distribution patterns of these species, and explore the main restrictive environmental factors. Initially, we employed the ecological niche model MaxEnt to predict the potential geographical distribution of target species. Following that, we overlaid the potential geographical distribution of each species, and we obtained the potential geographical distribution pattern of species richness on the spatial scale of the ecological niche model with a resolution of $0.05^{\circ} \times 0.05^{\circ}$. Ultimately, we also adopted geographically weighted regression (GWR) model to investigate the explanation capabilities of various environmental parameters on the potential distribution patterns. The results showed that the average AUC value of each species was between 0.80 and 1.00, which indicated that the simulation precision of the MaxEnt model for each species was good or excellent. Besides, the potential distribution areas of these species were between $826.33 \mathrm{~km}^{2}$ and $44,963.53$ $\mathrm{km}^{2}$. In addition, the average contribution values of the annual precipitation (Bio12), precipitation of coldest quarter (Bio19) and population density (Pop) were $25.92 \%, 15.86 \%$ and $17.95 \%$, respectively. Moreover, the goodness of fit $R^{2}$ and AIC value of the water model were 0.88 and 7,703.82, respectively, which indicated the water factor largely influenced the potential distribution of these species. The results of this study would be helpful for implementing long-term conservation and reintroduction for these species.
\end{abstract}

Keywords: biodiversity conservation, environmental explanations, geographically weighted regression (GWR), habitat suitability, MaxEnt, Northwest Yunnan, potential geographical distribution

\title{
1 INTRODUCTION
}

The geographical distribution pattern of species and utilizing species distribution models (SDMs) to predict the potential geographical distribution of species are one of the hot research issues in the fields of biogeography and biodiversity conservation (Gaston, 2000; Zhang \& Ma, 2008; Ning et al., 2018; Tripathi et al., 2019a). Studying the geographical distribution pattern and predicting the potential geographical distribution of species are of great significance for developing effective biodiversity conservation strategies (Zhang et al., 2019; Lazo-Cancino et al., 2020), preventing and managing the spread of invasive alien species (IAS) diffusion (Fernandes et al., 2019) and assessing the impact of climate change on species distribution (Lazo-Cancino et al., 2020), and they are also an effective means of protecting and managing some rare, endangered and/or threatened species.

The maximum entropy (MaxEnt) model is a species distribution model based on the environmental factors matching method, and is often used to predict the potential geographical distribution of species. The MaxEnt model employs the data of species distribution locations and environmental variables to jointly simulate the potential geographical distribution of species and has many advantages over other species distribution models, including easy operation and use, high simulation precision, good performance with incomplete datasets $(\mathrm{Li}$ et al., 2020). Currently, the MaxEnt is the most widely used species distribution model (Merow et al., 2013; Gong et al., 2015; Ning et al., 2018). The research results of Hernandez et al. (2006) and Deb et al. (2017) both showed that in the case of few geographical locations $(<10)$, even as low as 4 or 5 , the MaxEnt model can still produce effective prediction results with high precision. At present, the model has been applied to simulate and predict the potential geographical distribution of endemic species (e.g., Impatiens hainanensis ; Ning et al., 2018), national protected species (e.g., Phellodendron amurense ; Huang et al., 2018) and many other key species. 
It is helpful to improve the scientific understanding of the spatial relationship between species and environment by studying the impact of different types of environmental factors on the potential geographical distribution of species. The spatial distribution pattern of species diversity is related to variations in environmental factors (e.g., Latitude, elevation and climate) (Tripathi et al., 2019a). However, the relationship between them often has spatial non-stationarity (i.e., Relationship between independent and dependent variables will change with geographical location) (Gouveia et al., 2013). Geographically weighted regression (GWR) model, which is an extension of traditional regression model (e.g., Ordinary least squares, OLS) (Ștefănescu et al., 2017; Tripathi et al., 2019a; Tripathi et al., 2019b; Xue et al., 2020), has become one of the crucial spatial heterogeneity modeling tools (Lu et al., 2020). In recent years, many domestic and foreign scholars have carried out in-depth and extensive research in various fields by using GWR model, including social environmental factors and regional economy, regional house prices and pollution (McCord et al., 2018; $\mathrm{Xu}$ et al., 2019), the impacts of environmental heterogeneity and land use change on wild animal distribution (Liu et al., 2019; Wang et al., 2020; Xue et al., 2020), vegetation activity and climate change (Gao et al., 2019). However, there are few studies that in combination MaxEnt with GWR models to analyze the potential geographical distribution and explore environmental explanations for some key species, especially in biodiversity hotspot areas.

According to the Living Planet Report 2020 (https://www.wwf.org.uk/press-release/living-planet-report2020), published by World Wide Fund for Nature (WWF) and Zoological Society of London (ZSL), population sizes of mammals, birds, fish, amphibians and reptiles have fallen an average of $68 \%$ globally. Northwest Yunnan of China is one of the global biodiversity hotspots (Myers et al., 2000; Ye et al., 2020a; Ye et al., 2020b). Plenty of rare, endangered, threatened and endemic species that need critical conservation are distributed in this area (Yang et al., 2017). In recent decades, due to the interference of human activities (e.g., Mining and collecting herbs) and the influence of the external natural environment, especially climate change, the populations and distribution area of some rare, endangered and threatened species have been decreasing (Yu et al., 2014). Living Planet Report 2020 also stated that from 2000 to 2018, the species habitat index dropped by $2 \%$, which indicated that the habitat quality of species shows a general trend of rapid decline. In addition, some species have the characteristics of geographical isolation and narrow distribution (Wang et al., 2013), as a result, their survival and development are faced with severe threats. Therefore, it is urgent to protect these key species and their suitable habitats in this area. In order to protect these key species reasonably and effectively, their geographical distribution must be clear first. However, at present, we are still unclear about the potential geographical distribution and main limited environmental factors for these key species in Northwest Yunnan.

Therefore, in this study, 25 key species were the focus of analysis, including some rare, endangered and/or national protected key higher plant species in Northwest Yunnan. Initially, we adopted the method of combining the MaxEnt model together with GWR model to predict the potential geographical distribution of each species on the grid map with a resolution of $0.05^{\circ} \times 0.05^{\circ}$ (for more details about resolution, see Ye et al., 2020a). Then, we overlaid the potential geographical distribution of each species, and obtained the potential geographical distribution pattern of species richness on the spatial scale of the ecological niche model with a resolution of $0.05^{\circ} \times 0.05^{\circ}$. Ultimately, we analyzed the explanation capabilities of various environmental factors on the potential geographical distribution patterns of these key species, and explored the main restrictive environmental factors. These research results would contribute to a more comprehensive understanding of the potential geographical distribution pattern of some key higher plant species in Northwest Yunnan, and would provide a scientific basis for the conservation and management of suitable habitat for rare, endangered and many other key species in this region. 


\section{MATERIALS AND METHODS}

\subsection{Study area and species data}

Northwest Yunnan is located in the mountains of southwest China, and lies to the Northwestern part of Yunnan Province (Figure 1). The area is situated on the transition zone between the Qinghai-Tibetan Plateau (QTP) and the Yunnan-Guizhou Plateau (YGP), and is seated in the Longitudinal Range-Gorge Region (LRGR) of the Hengduan Mountains in the east of the Himalayas, and is simultaneously located in the Three Parallel Rivers Region (TPRR) (i.e., Jinsha River, Lancang River, and Nujiang River) (Yang, 2002). Massive variations in terrain and climate in Northwest Yunnan (for more details, see Ye et al., 2020a), as well as the resulting rich and diverse special habitats, provide habitats for special species, especially for rare and endangered species. In particular, alpine ecosystem and plateau lake ecosystem that contain a large number of rare and endangered species (Tao et al., 2016). The special terrain and diverse climate make this area become one of the most concentrated and abundant regions of biodiversity in China (Xue \& Wu, 2016; Ye et al., 2020b). In addition, Northwest Yunnan is also considered to be one of the world's 36 biodiversity hotspots (Conservation International, https://www.conservation.org/priorities/biodiversityhotspots). The spatial variation of environmental factors make the distribution pattern of species diversity more complicated. Therefore, Northwest Yunnan has become an ideal region to discuss the distribution pattern of species diversity and simulate the distribution of potential suitable habitats.
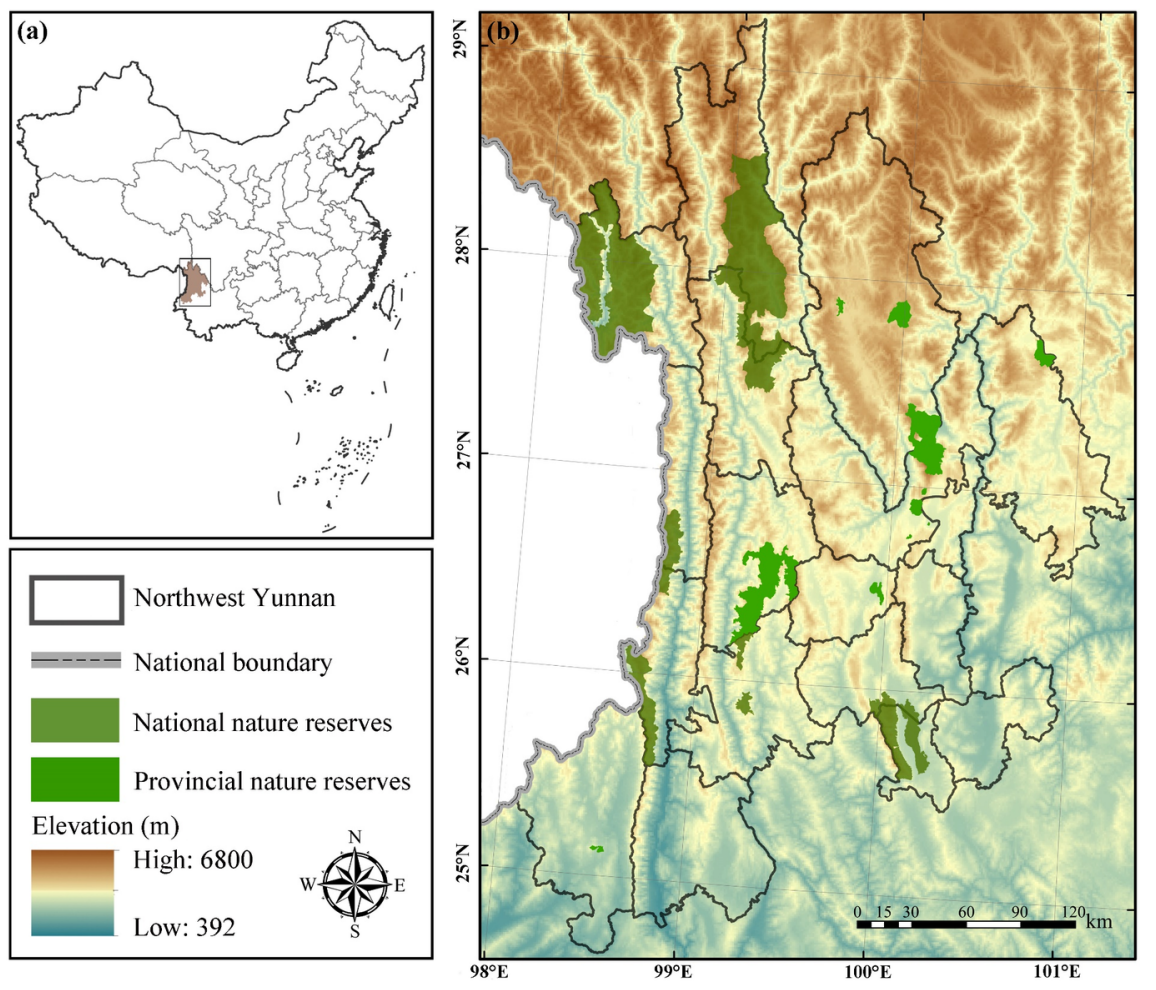

FIGURE 1 Map of the study area. (a) The location of Northwest Yunnan in China; (b) The topographic map of Northwest Yunnan and the distribution of national nature reserves (NNRs) and provincial nature reserves (PNRs) in this region

Combined with the results of our previous research, a total of 114 key higher plant species in Northwest Yunnan were suggested (Ye et al., 2020a). The information used to construct the dataset (e.g., Taxonomic 
level, threatened level and geo-referenced records) were obtained from field survey in nearly a decade and main virtual herbarium in China (for more details, see Ye et al., 2020a). In this study, we selected a total of 25 species (including 314 distribution records) from 114 key higher plant species (comprises 941 geo-referenced records) (see selection standards below). The selection was based on the combination of the following standards: (1) occurrence records: in order to improve the accuracy of the MaxEnt model prediction as much as possible, the number of species distribution records should not less than four; (2) simulation accuracy: MaxEnt model should have good or excellent simulation accuracy for included species (for more details, see section 2.4.1).

\subsection{Environmental variables}

Based on previous studies (Nieto et al., 2015; Ștefănescu et al., 2017; Zhang et al., 2019; Liu et al., 2019), we initially selected 24 environmental variables that may affect species distribution to model the current potential geographical distribution patterns (Table 1). Above all, we divided these variables into five groups according to their categories. After that, 24 environmental factors were resampled and reprojected to an equal-area grid system with the same spatial resolution $\left(0.05^{\circ} \times 0.05^{\circ}\right)$ as species richness (Wang et al., 2018). Then we employed the ArcGIS 10.4 software (Esri; Redlands, California, USA) to extract the raster data of environmental variables.

In order to avoid multicollinearity of environmental parameters that might result in model over-fitting, we calculated Pearson correlation coefficient between each variable with the help of $\mathrm{R}$ 3.5.2 software (https://www.r-project.org/). After performed a multicollinearity test, we finally obtained 11 independent environmental variables $(r<0.8)$ to model the potential geographical distribution of each species (Zhang et al., 2019; Mukherjee et al., 2020) (Figure 2).

\subsection{Model construction}

We constructed two models in this research: one was for predicting the potential geographical distribution area of species; the other was for analyzing the main environmental factors influencing the potential distribution of species.

\subsubsection{Construction of the MaxEnt model}

Phillips et al. (2004) developed the MaxEnt model based on the theory of maximum entropy, which was applied to the study of simulating species distribution (Phillips et al., 2006; Zhang et al., 2011). The model can combine species occurrence localities and environmental parameters to predict the habitat suitability, and then explores the possible distribution of the species in the study area (Phillips et al., 2006; Phillips \& Dudík, 2008; Zhang et al., 2019).

In this study, the latitude and longitude of species distribution sites and the independent environmental factors in Northwest Yunnan were simultaneously imported into the MaxEnt model (Version 3.3.3k) to construct the correlation function between species and the environment. Usually, the prediction results of the MaxEnt model are related to some set parameters, such as the max number of background points (BC), regularization multiplier (RM), and feature combination (FC) (Zhu et al., 2018). MaxEnt is applied to run with the following modeling regulations: (1) for species with $<10$ distribution records linear features were applied; (2) for species with 10-14 records quadratic features were utilized, and; (3) species with $>15$ records hinge features were employed (Zhang et al., 2012; Zhang et al., 2017). In this research, we set the RM value to $[0.5,3]$, the step size was 0.5 ; the $\mathrm{BC}$ value set as $[5000,15000]$, the step size was 5000 . After that, we applied the linear, quadratic and hinge features to construct the MaxEnt model, respectively. In addition, $75 \%$

of species distribution locations were randomly selected as training data to build the model, and the remaining $25 \%$ of the species distribution locations were used as testing data for model validation (Guan et al., 2018; 
Zhang et al., 2019). The maximum iterations was set as 500, and the number of replicate runs was set as 10 or 20 .
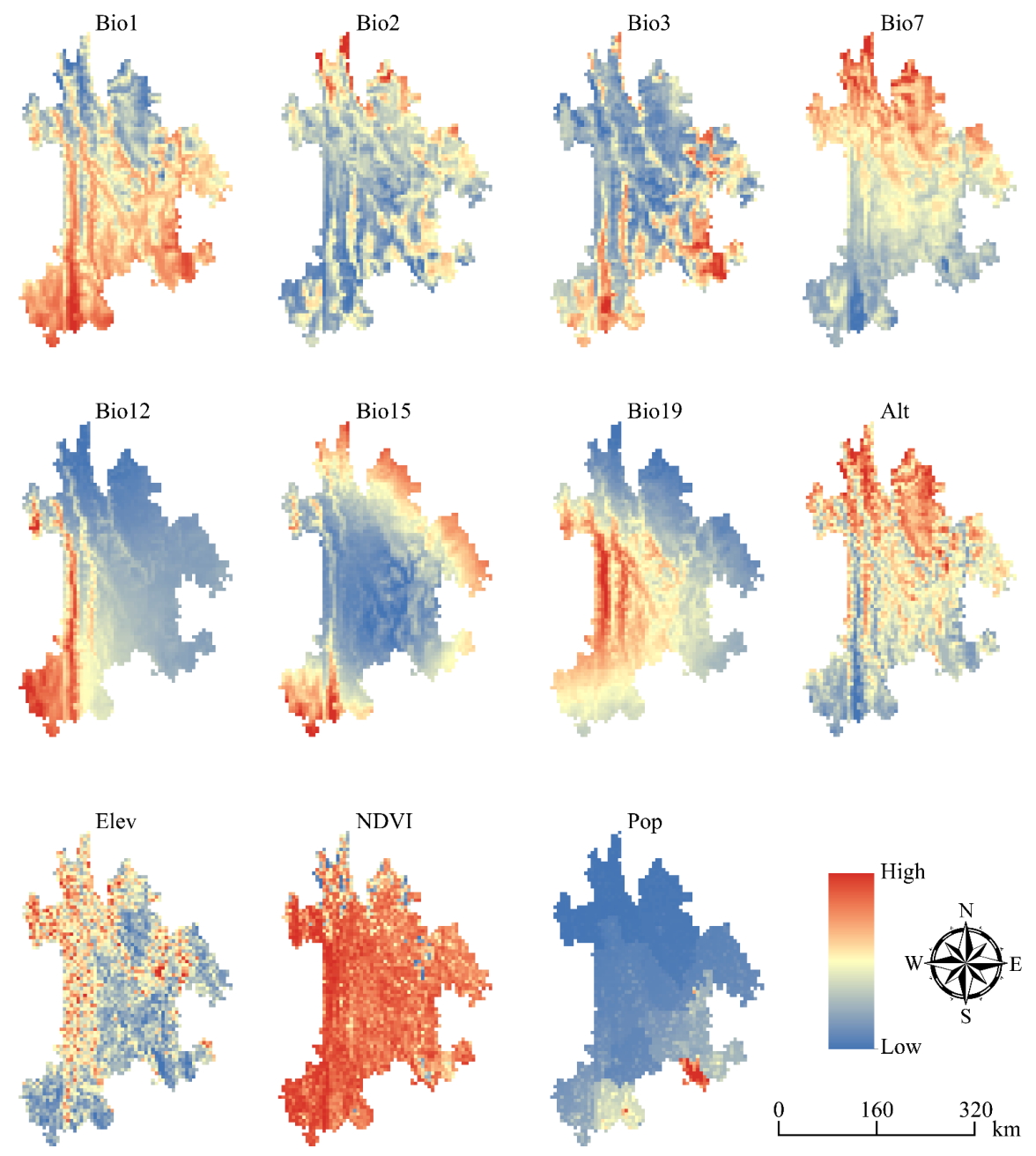

FIGURE 2 Independent environmental variables used to model the potential geographical distribution of each species in Northwest Yunnan

\subsubsection{Construction of the GWR model}

Fotheringham et al. (1996) proposed the GWR model based on the thought of local smoothing and the summary of local regression analysis and variable parameter research. GWR is an extension and improvement of the traditional global linear regression (e.g., OLS) which adds geographical locations (i.e., Spatial factors) to the regression parameters, and also considers the spatial weights of adjacent points (Han et al., 2016). In addition, GWR model is a local regression model, which can profoundly explain the spatial non-stationarity relationship between response variables and explanatory variables by decomposing global parameters into local parameters (Tripathi et al., 2019a). The regression equation can be developed as (Han et al., 2016; 
Tripathi et al., 2019b):

$$
\mathrm{y}_{\mathrm{i}}=\beta_{\mathrm{i} 0}\left(\mathrm{u}_{\mathrm{i}}, \mathrm{v}_{\mathrm{i}}\right)+\sum_{\mathrm{k}=1}^{\mathrm{p}} \beta_{\mathrm{ik}}\left(\mathrm{u}_{\mathrm{i}}, \mathrm{v}_{\mathrm{i}}\right) \mathrm{x}_{\mathrm{ik}}+\varepsilon_{\mathrm{i}}
$$

Where $k=1, p$ explanatory variables, $\epsilon_{l}$ denotes the random error term at position $i$. In addition, $\left(u_{i}, v_{i}\right)$ represents the geographic coordinate or spatial location the of each observation, $\beta_{l_{0}}\left(u_{i}, v_{i}\right)$ is the intercept at position $i, \beta_{\imath k}\left(u_{i}, v_{i}\right)$ denotes the local regression coefficient at position $i$. When $\beta{ }_{1 k}=\beta_{2 k}=\ldots$ $=\beta_{\nu \kappa}$, it indicates that the GWR model is transformed into an ordinary linear regression model. In this study, the potential species richness within each grid were used as dependent variables and environmental factors were used as independent variables to investigate the explanation capabilities of different categories of environmental parameters on the potential geographical distribution patterns of species.

According to the Tobler's first law (TFL) of geography (Tobler, 1970), the basic principle of the GWR model to calculate the weight is "the closer the distance, the higher the assigned weight; on the contrary, the lower the assigned weight (Fotheringham et al., 2002)". Therefore, the weight can be calculated by a monotonically decreasing function in space distance with $[0,1]$ as the value range. This type of function is called as kernel function (Lu et al., 2020). The GWR method usually employs a Gaussian model as a weight function, where bandwidth is a function that describes the weight and the distance and is considered as an important control parameter in weight calculation (Gao et al., 2019). The function is expressed as (Wang et al., 2020):

$\omega_{\imath \vartheta}=\exp \left(-\frac{\mathrm{d}_{\mathrm{ij}}^{2}}{\mathrm{~b}^{2}}\right)$

Where $\omega_{l \vartheta}$ denotes the distance weight of observation location $i$ and $j, d_{i j}$ is the Euclidean distance between location $i$ and $j$, and $\mathrm{b}$ represents the bandwidth. When the distance between location $i$ and $j$ is larger than $\mathrm{b}, \omega_{\imath \vartheta}$ is equal to 0 ; when the distance between location $i$ and $j$ is equal to $0, \omega_{l \vartheta}$ is equal to 1 .

\subsection{Model evaluation}

\subsubsection{Evaluation of the MaxEnt model}

We adopted AUC value to evaluate the fitting accuracy of the MaxEnt model. The model fitting precision can be evaluated as failed if AUC value is between 0.50 and 0.60 , poor if AUC value is between 0.60 and 0.70, fair if AUC value is between 0.70 and 0.80 , good if AUC value is between 0.80 and 0.90 , and excellent if AUC value is between 0.90 and 1.00 (Phillips et al., 2006; Zhang et al., 2019). In addition, the suitability maps were calculated employing the logistic output of the Maxent, and the range of habitat suitability index (HSI) value we had obtained was $[0,1]$. According to a large number of previous studies and the expert experience method, we reclassified HSI value into four grades by Natural Breaks in ArcGIS 10.4 software: $0-0.20$ is low, $0.20-0.40$ is medium, 0.40-0.60 is high, and 0.60-1.00 is optimal (Convertino et al., 2014; Yi et al., 2017). In order to conservatively estimate the suitable potential geographical distribution area of species, we considered grids with the HSI value larger than or equal to 0.40 as the suitable potential distribution area.

\subsubsection{Evaluation of the GWR model}

In this study, we used the package 'spgwr' of $\mathrm{R}$ software to select bandwidth by adopting Gaussian function and employed Akaike Information Criterion (AIC) to confirm the optimal bandwidth. Generally, regression residual is an evaluation value of the fitting goodness of the model, including residual sum of squares (RSS) and residual standard deviation (Sigma), and these two values should be as small as possible. In addition, $R^{2}$ and AIC value can also reflect fitting goodness of the model. The higher $R^{2}$, and the lower AIC value, indicating the better fitting effect of the model (Li et al., 2017; Liu et al., 2019). When the difference in 
the AIC value ([?]AIC) of the two models is greater than three, then the model with smaller AIC value has better fitting effect (Han et al., 2016; Xue et al., 2020).

\section{RESULTS}

\subsection{Species distribution records}

On the basis of the selection criteria in section 2.1, we finally identified 25 rare, endangered and/or national protected species with high simulation accuracy, belonging to 23 genera and 19 families (Table 2). We had organized the collected species distribution data and obtained a total of 314 distribution records of species, and further understood the distribution status of each species in Northwest Yunnan. The result suggested that there were at least four distribution records for each species, as a result, detailed distribution records were shown in Table 2. Among them, Dipentodon sinicus and Psammosilene tunicoides had more occurrence records, with a total of 59 and 41, respectively. They were mainly distributed in the vicinity of the Gaoligong Mountain National Nature Reserve and several PNRs (i.e., Napahai, Bitahai, Haba Snow Mountain and Yulong Snow Mountain). However, Anisodus tanguticus, Camellia reticulata and Paris rugosa owned few distribution records, with four for each. They were scattered in the vicinity of Gaoligong Mountain, Baima Snow Mountain and Cangshan Erhai NNRs.

TABLE 2 The checklist of species used in this study was according to IUCN Red List criteria and The National Key Protected Wild Plants List, specifically: 1) Threat level: referenced IUCN Red List criteria, Vulnerable (VU), Endangered (EN), Critically Endangered (CR); 2) Protection level: 1 represents The National Key Protected Wild Plants List (the first), 2 represents The National Key Protected Wild Plants List (the second), I denotes national first-level protected species, II denotes national second-level protected species. Samples: the distribution records of the 25 rare, endangered and/or national protected species as the input of the MaxEnt modelling

\begin{tabular}{lllll}
\hline Family & Species & Threat level & Protection level & Samples \\
\hline Actinidiaceae & Actinidia pilosula & VU & $2(\mathrm{II})$ & 9 \\
Solanaceae & Anisodus acutangulus & $\mathrm{CR}$ & - & 14 \\
Solanaceae & Anisodus tanguticus & - & $1(\mathrm{II})$ & 4 \\
Aristolochiaceae & Aristolochia delavayi & EN & - & 7 \\
Orchidaceae & Bulleyia yunnanensis & EN & $2(\mathrm{II})$ & 10 \\
Theaceae & Camellia reticulata & VU & $2(\mathrm{II})$ & 4 \\
Ranunculaceae & Coptis teeta & $\mathrm{CR}$ & $2(\mathrm{II})$ & 5 \\
Orchidaceae & Cypripedium guttatum & $\mathrm{EN}$ & $2(\mathrm{I})$ & 9 \\
Celastraceae & Dipentodon sinicus & - & $1(\mathrm{II})$ & 59 \\
Orchidaceae & Diphylax uniformis & VU & $2(\mathrm{II})$ & 6 \\
Campanulaceae & Echinocodon lobophyllus & $\mathrm{CR}$ & $2(\mathrm{II})$ & 7 \\
Liliaceae & Fritillaria delavayi & VU & - & 8 \\
Orchidaceae & Gymnadenia crassinervis & VU & $2(\mathrm{II})$ & 5 \\
Magnoliaceae & Magnolia rostrata & VU & $1(\mathrm{II})$ & 5 \\
Compositae & Nouelia insignis & VU & $2(\mathrm{II})$ & 25 \\
Hydrocharitaceae & Ottelia acuminata & VU & - & 7 \\
Liliaceae & Paris dulongensis & $\mathrm{CR}$ & $2(\mathrm{II})$ & 7 \\
Liliaceae & Paris rugosa & EN & $2(\mathrm{II})$ & 4 \\
Caryophyllaceae & Psammosilene tunicoides & EN & $1(\mathrm{II})$ & 41 \\
Crassulaceae & Rhodiola atuntsuensis & EN & $2(\mathrm{II})$ & 8 \\
Berberidaceae & Sinopodophyllum hexandrum & - & $2(\mathrm{II})$ & 26 \\
Dryopteridaceae & Sorolepidium glaciale & - & $1(\mathrm{I})$ & 25 \\
Taxodiaceae & Taiwania cryptomerioides & VU & $1(\mathrm{II})$ & 4 \\
& & & &
\end{tabular}




\begin{tabular}{lllll}
\hline Family & Species & Threat level & Protection level & Samples \\
\hline Combretaceae & Terminalia myriocarpa & VU & $1(\mathrm{II})$ & 5 \\
Tetracentraceae & Tetracentron sinense & EN & $1(\mathrm{II})$ & 10 \\
\hline
\end{tabular}

\subsection{MaxEnt model performance}

The average AUC value of each species was between 0.80 and 1.00, indicating that the simulation effect of the model on each species was good or excellent. Among them, the minimum average AUC value was 0.80 and the maximum was 0.99 (Figure 3), which demonstrated that the constructed MaxEnt model could be used to predict and analyze the potential geographical distribution of 25 rare, endangered and/or national protected species in Northwest Yunnan. 


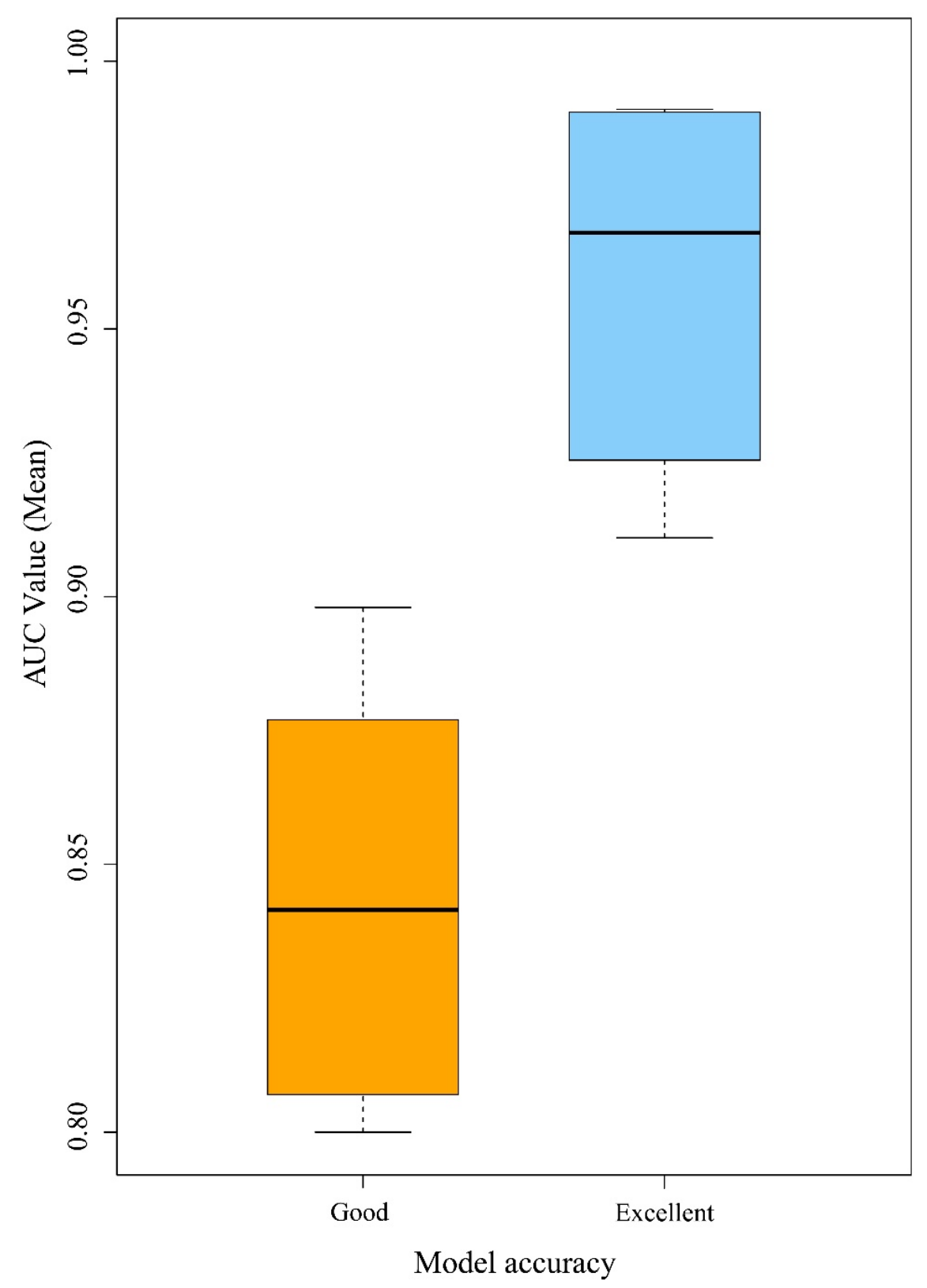

FIGURE 3 The AUC value calculated and output by the Maxent model

\subsection{Environmental variable contribution}

The percentage contribution values of environmental variables to the predicted results of the MaxEnt model were defined through heuristics, and depended on the specific path that MaxEnt codes used to provide best solutions (Li et al., 2020). In this research, the percentage contribution values were the average contribution values established over cross-validation and repeated runs for each species ( $\mathrm{Li}$ et al., 2020). The results showed that among the 11 independent environmental variables, annual precipitation (Bio12), precipitation of coldest quarter (Bio19) and population density (Pop) had higher average contribution rates to the species 
distribution model than other environmental variables. Their average contribution values to the model were $25.92 \%, 15.86 \%$ and $17.95 \%$, respectively, and the cumulative contribution value accounted for $59.73 \%$ of the total contribution value of all environmental factors to the model (Figure 4). However, compared with other environmental factors, mean diurnal range (Bio2) and altitude (Alt) had the lowest average contribution values to the species distribution model. Their average contribution values to the model were $1.07 \%$ and $1.64 \%$, respectively, and the accumulated contribution value accounted for $2.71 \%$ of the total contribution value of all environmental variables to the model (Figure 4).

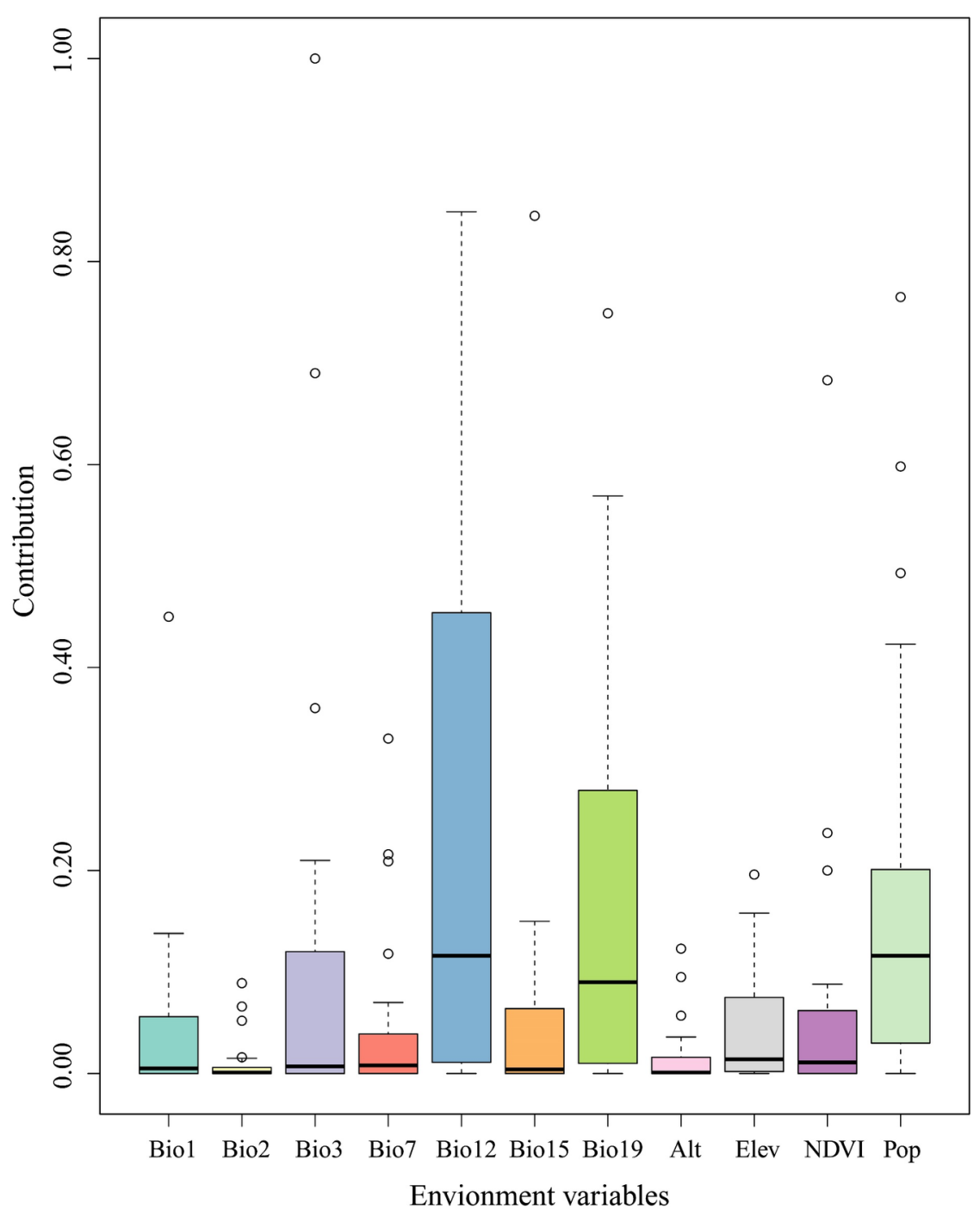

FIGURE 4 Contribution value of environmental variables to predicting result of the MaxEnt model

\subsection{Potential geographical distribution of species}

HSI is an important or key factor that affects the survival and development of species. It refers to the potential ability of a habitat to support the survival of a particular species. The results of the study revealed that potential distribution areas of species appears to be decreasing with the improvement of habitat suitability (Figure 5), which indicated that the remaining natural habitat suitable for species was becoming less and 
less. In addition, the research results also indicated that the species with a larger potential distribution areas were Echinocodon lobophyllus , Gymnadenia crassinervis, Rhodiola atuntsuensis and Aristolochia delavayi . Their potential distribution areas were $44,963.53 \mathrm{~km}^{2}, 30,830.51 \mathrm{~km}^{2}, 22,481.77 \mathrm{~km}^{2}$ and $22,396.28 \mathrm{~km}^{2}$, respectively, accounting for $56.36 \%, 38.64 \%, 28.18 \%$ and $28.07 \%$ of the total area of Northwest Yunnan (Table 3; Figure 6). The species with smaller potential distribution areas were Diphylax uniformis, Paris dulongensis and Terminalia myriocarpa. Their potential distribution areas were $2,137.05 \mathrm{~km}^{2}, 1,054.28 \mathrm{~km}^{2}$ and $826.33 \mathrm{~km}^{2}$, respectively, occupying only $2.68 \%, 1.32 \%$ and $1.04 \%$ of the total area of Northwest

Yunnan (Table 3; Figure 6). Generally, the potential distribution areas of each species were relatively concentrated. The HSI values of the mid-western, mid-eastern and northern regions of the study area were between 0.40 and 1.00, which were deemed the main concentration area of the potential distribution of species. Furthermore, the area of high suitability plaques (i.e., Sum area of high suitability level habitats, where 0.40 [?] HIS < 0.60) was larger than the area of optimal suitability plaques (i.e., Sum area of optimal suitability level habitats, where 0.60 [?] HIS < 1.00) (Table 3; Figure 6).

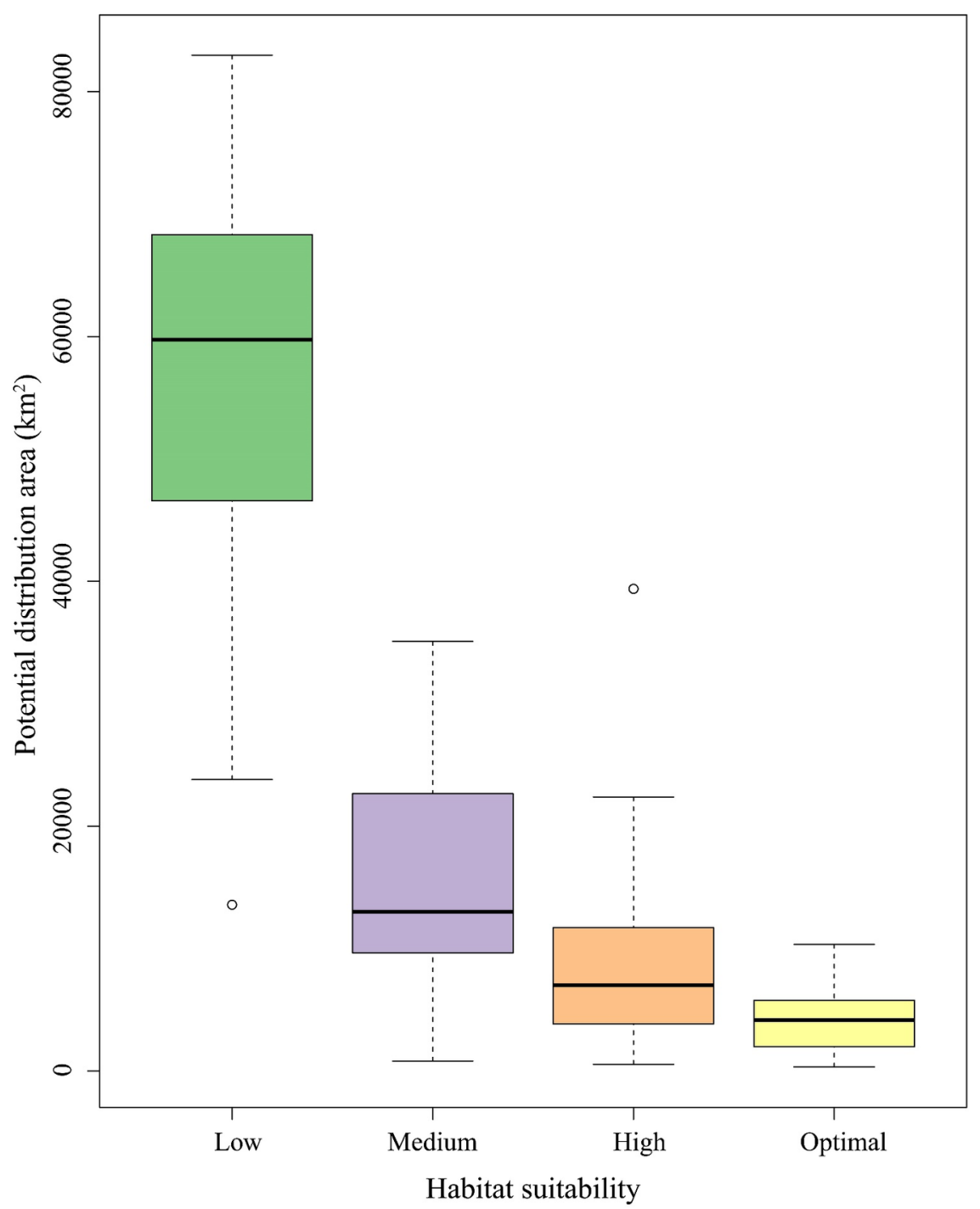

FIGURE 5 Potential distribution area of habitat for various suitability levels 

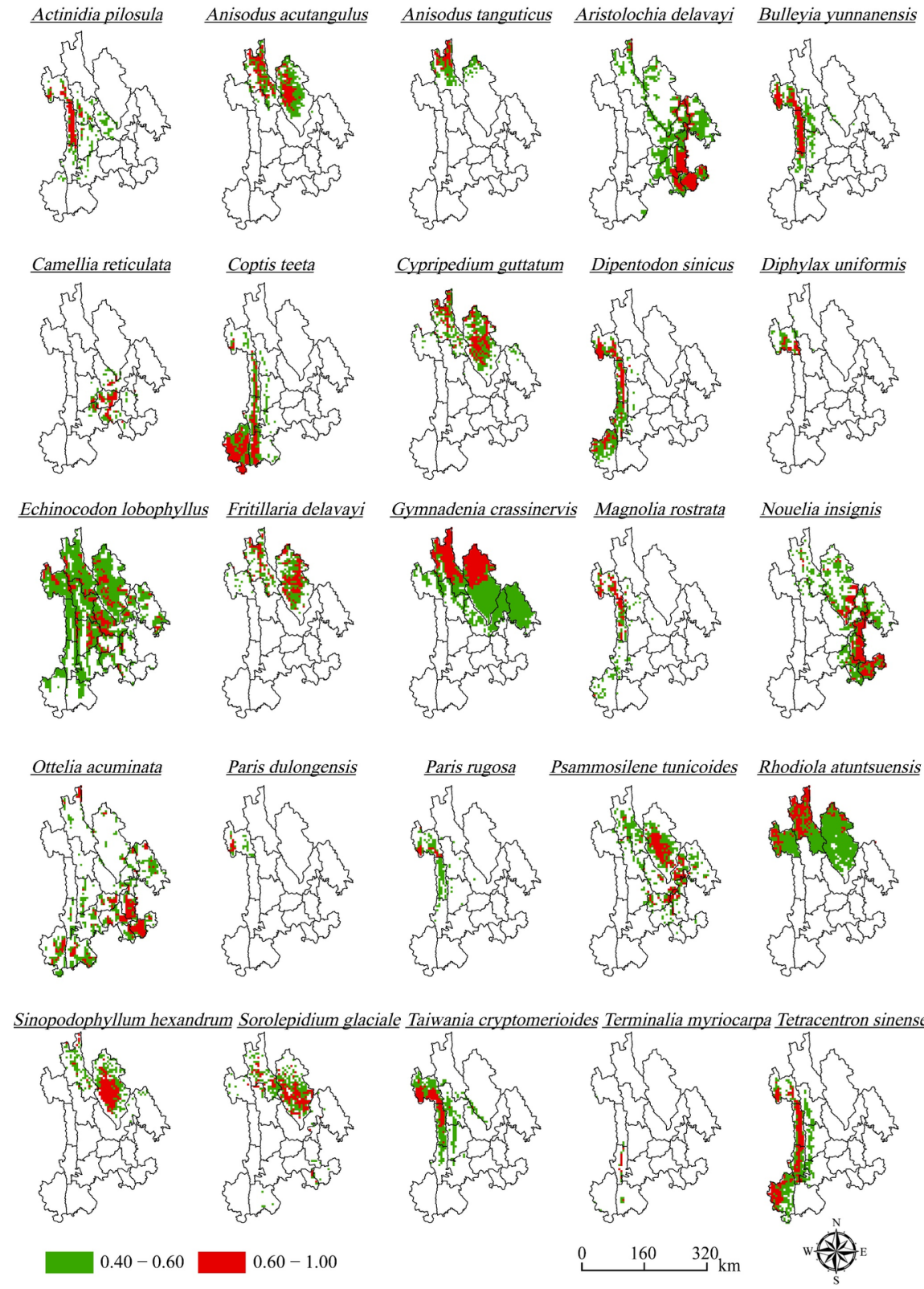

FIGURE 6 Potential distribution area of each species predicted by the MaxEnt model. The habitat suitability will be evaluated as high, if HIS value is between 0.40 and 0.60 , and optimal if HIS value is between 0.60 and 1.00

In addition, we adopted ArcGIS 10.4 software to superimpose the appropriate potential distribution areas of each species (HSI [?] 0.4 ) to obtain the potential distribution pattern of species richness (Figure 7). The results showed that on the grid scale with a resolution of $0.05^{\circ} \times 0.05^{\circ}$, the potential species richness of each grid ranged from 0 to 12 . Through a combination of the distribution of the existing national and provincial nature reserves in Northwest Yunnan together with the administrative division of this region (for more details, see Ye et al., 2020a), we found that part of the grids with the highest potential species richness were located near Baima Snow Mountain and Gaoligong Mountain NNRs, while the other part of the grids with the highest potential species richness were situated in Shangri-La County (Figure 7). 


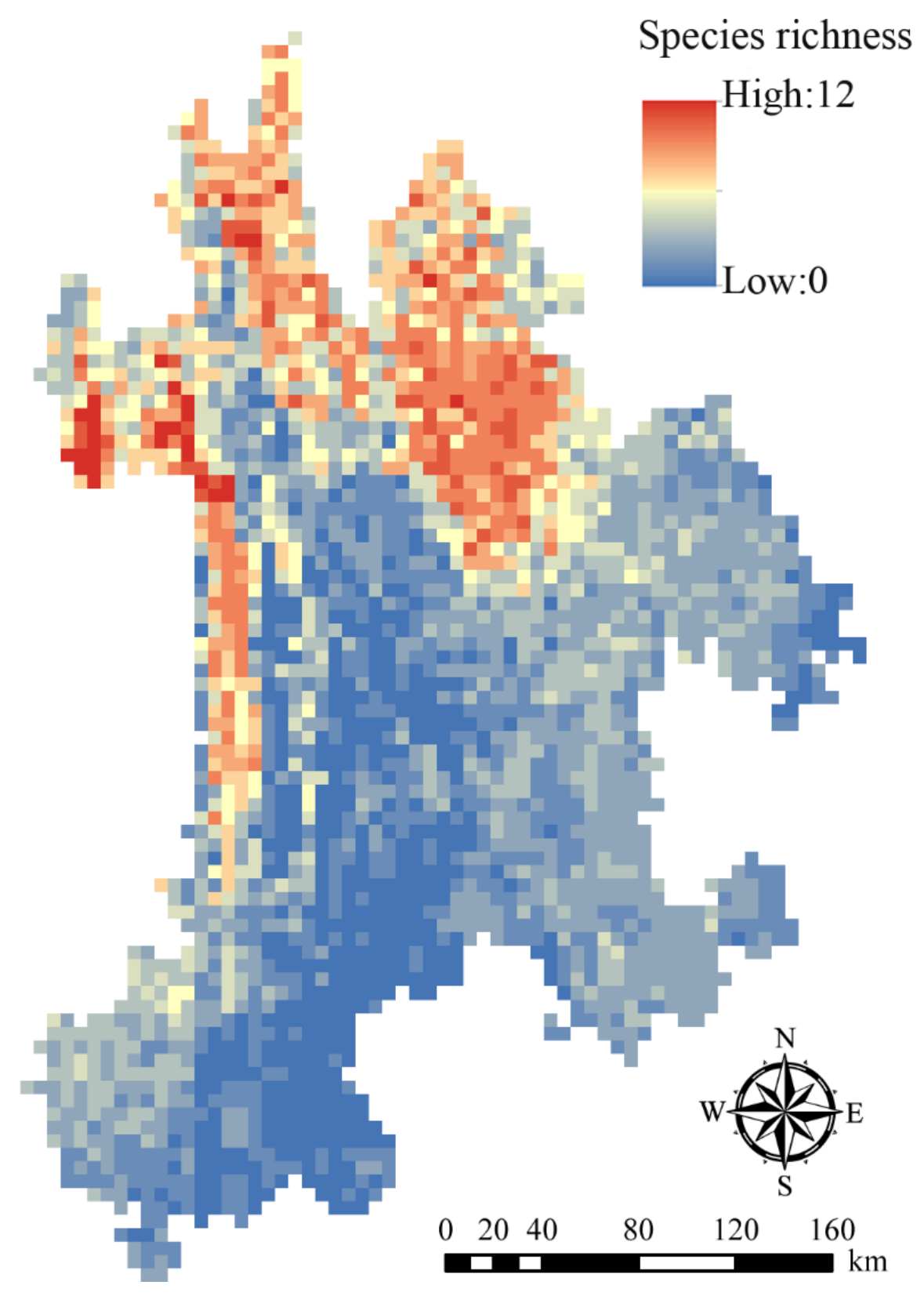

FIGURE 7 Distribution pattern of potential species richness of 25 rare, endangered and/or national protected key higher plant species in Northwest Yunnan

\subsection{Environmental explanations for potential distribution of species}

According to the category of environmental factors, we employed the package 'spgwr' of the software $\mathrm{R}$ and constructed six different types of environmental factor models to explain the potential distribution of species through the GWR model (Table 4). The research results indicated that the human activity model had a lower interpretation rate than other models, which appeared a goodness of fit $R^{2}$ and AIC value of 0.83 and 8,850.15, respectively. However, the goodness of fit $R^{2}$ and AIC value of the water model were 0.88 and 7,703.82, respectively, which gave a higher explanation rate than other models, indicating that the 
water factor largely influenced the potential distribution of species. In addition, the goodness of fit $R^{2}$ and AIC value of the comprehensive model were 0.92 and 6,785.26, respectively, and the difference in the AIC value ([?]AIC) with other models was greater than three, demonstrating that the comprehensive model had a better simulation effect on the potential distribution of species. The results also revealed that multiple environmental variables were not mutually exclusive, and the potential distribution of species was the result of the combined effects of various environmental factors.

TABLE 4 Fitting effects of different models on the potential distribution of species

\begin{tabular}{lllllll}
\hline $\begin{array}{l}\text { Model }\left(0.05^{\circ}\right. \\
\left.\times 0.05^{\circ}\right)\end{array}$ & $\begin{array}{l}\text { Bandwidth } \\
(\mathrm{km})\end{array}$ & Sigma & RSS & AIC & [?]AIC & $R^{2}$ \\
\hline $\begin{array}{l}\text { Temperature } \\
\text { model }\end{array}$ & 10.37 & 1.04 & $2,372.18$ & $7,939.56$ & $1,154.30$ & 0.88 \\
$\begin{array}{l}\text { Water model } \\
\begin{array}{l}\text { Productive } \\
\text { model }\end{array}\end{array}$ & 9.45 & 1.00 & $2,229.88$ & $7,703.82$ & 918.56 & 0.88 \\
$\begin{array}{l}\text { Topographical } \\
\text { model }\end{array}$ & 9.21 & 1.15 & $2,729.22$ & $8,382.65$ & $1,597.39$ & 0.86 \\
$\begin{array}{l}\text { Human } \\
\text { activity model }\end{array}$ & 6.64 & 1.04 & $2,376.74$ & $7,900.40$ & $1,115.14$ & 0.88 \\
$\begin{array}{l}\text { Comprehensive } \\
\text { model }\end{array}$ & 14.96 & 1.24 & $3,253.97$ & $8,850.15$ & $2,064.89$ & 0.83 \\
\hline
\end{tabular}

\section{DISCUSSION}

\subsection{The potential geographical distribution of species}

Habitat is a vital place for survival, reproduction and population development of species. Its quality can directly influence the distribution, quantity and survival rate of species (Hall et al., 1997; Zhang et al., 2019). We utilized the MaxEnt model to predict the potential geographical distribution of 25 rare, endangered and/or national protected plant species in Northwest Yunnan. The results showed that the potential distribution area (i.e., Region where HSI [?] 0.4) of each species was between $826.33 \mathrm{~km}^{2}$ and $44,963.53 \mathrm{~km}^{2}$, which indicated that these species had obvious differences in their adaptability to environmental factors such as the topography and climate in Northwest Yunnan. The potential distribution area of these target species were mainly concentrated in the mid-western, mid-eastern and northern parts of the study area, which was in good agreement with the prediction results of the potential distribution area which studied by Zhuang et al. (2018a). The prediction results of this study will provide possible new areas for species distribution and field investigation. In addition, the potential distribution area of species overlapped greatly in the mid-western and northern parts of Northwest Yunnan. We roughly divided them into two parts. One part was close to the Gaoligong Mountain and Baima Snow Mountain NNRs, which were almost consistent with the hotspot distribution of key higher plant species in Northwest Yunnan (Ye et al., 2020a). Similarly, the other part was located in Shangri-La County, which might be related to the fact that Shangri-La is situated at the core area of the Three Parallel Rivers World Natural Heritage Site (Yang et al., 2013), with abundant landscape types, vegetation types, and ecosystem types. Consequently, the results reflected that these regions mentioned above will play a crucial role in biodiversity conservation in the future.

\subsection{A model used to predict the distribution of species}

The model prediction method can help to compensate for the difficulty in field investigation. The vertical peaks and horizontal valleys in Northwest Yunnan greatly limit the accessibility of field surveys. Hence, by 
combining the model prediction with field investigation, the field survey can be carried out in the order of habitat suitability, with priority given to the field investigation in the optimal suitability distribution area and the potential distribution area that has not been studied. In addition, the completeness, accuracy and reliability of species geographical distribution data are important and key links of division of key biodiversity areas. Meanwhile, the accuracy of the data and the precision of the model prediction are also mutually promoted (Zhang et al., 2016; Wu et al., 2016; Zhuang et al., 2018a). In this study, we tried our best to collect a lot of species distribution data through multiple approaches, but there are still some species with relatively less distribution data. For example, Coptis teeta is also distributed in Myanmar and other countries. Therefore, more species distribution data must be collected to construct a more accurate species distribution model. In addition, the distribution of species is not only determined by topography, climate and edaphic factors, but also influenced by social and economic structure, land use type, human disturbance and other social factors. In some cases, due to the influence of the local microenvironment, the areas predicted to be of lower suitability levels are actually the distribution areas of species. Therefore, the results obtained in this study are only advisory. A more precise and accurate potential distribution prediction needs to be supported by more comprehensive social and environmental factors and more precise and more reliable species distribution information.

\subsection{Environmental explanations for the potential distribution of species}

From an ecological point of view, environmental factors can affect the spatial distribution of species, as well as their habitat suitability (Zhang et al., 2019). In this study, we found that the cumulative contribution rate of Bio12 (25.92\%), Bio19 (15.86\%) and Pop (17.95\%) to the MaxEnt model prediction results reached $59.73 \%$. Furthermore, the contribution rate of Bio12 was the highest, which was consistent with the results obtained by Zhuang et al. (2018). In addition, the $R^{2}$ values of the GWR model were all above 0.80, indicated that the model has a reliable goodness of fit for explaining the potential distribution of species. Moreover, the water model $\left(R^{2}=0.88\right.$, AIC $\left.=7703.82\right)$ showed a higher explanation rate compared to other single models, followed by the temperature model $\left(R^{2}=0.88\right.$, AIC $\left.=7939.56\right)$ and topographical model $\left(R^{2}=0.88\right.$, AIC $\left.=7900.40\right)$, which were second only to the water model in their interpretation effect on the potential distribution of species. Accordingly, this result suggested that climate (temperature and water factor) and habitat heterogeneity (topographical factor) could play an important role in the prediction of potential distribution areas of species, which was coincide with the research results of Stefănescu et al. (2017). However, compared with all single models, the comprehensive model $\left(R^{2}=0.92\right.$, AIC $\left.=6785.26\right)$ that combines all environmental factors had a better goodness of fit, which indicated that the potential distribution of species was the result of the combined effects of various environmental factors (Wang et al., 2018). The main thing worth mentioning is that, rare and endangered species are usually restricted to specialized edaphic or topographic or other environmental conditions which occupy a quite fraction of their climatically suitable range. Therefore, on the basis of this study, it is necessary to study the effects of other relevant environmental factors on the potential distribution of species.

\subsection{Suggestions for the protection of rare and endangered plant species}

In recent decades, due to the disturbance of human activities and the impacts of the external natural environment, especially climate change, the population size and distribution area of some rare, endangered and/or threatened species had been declining (Yu et al., 2014). Therefore, understanding the habitat suitability of species and its influencing factors is the basis of protecting rare and endangered plant species (Zhang et al., 2019). Habitat suitability plays an important role in the survival and development of species. Hence, habitat suitability assessment is the first step of effective conservation and scientific management of species, and can provide scientific basis for relevant departments to formulate valid conservation strategies. It has become a resultful method to protect rare and endangered species by scientifically predicting the potential distribution areas and habitat suitability levels of species and planning wild nature reserve in the best suitable areas (Xiao et al., 2011; Xu et al., 2015). The results of this study revealed that the habitat suitability of species 
near Gaoligong Mountain and Baima Snow Mountain NNRs and Shangri-La Country was relatively high, and these areas were also the core regions for the distribution of rare, endangered and/or national protected species in Northwest Yunnan. For this reason, it is suggested that to strengthen the conservation of these areas. In addition, Shangri-La Country had more habitat suitability distribution areas for species, but there were only three PNRs with a small area, namely, Napahai, Bitahai and Haba Snow Mountain PNRs (Ye et al., 2020a). It is recommended that appropriate expansion of the nature reserve should be carried out, with measures combining in-situ and ex-situ conservation to strengthen the protection of species in a state of isolation and/or fragmentation. In addition, the species distribution model is an estimate of the potential distribution of species, and its essence is prediction research. Therefore, the results of the model simulation cannot be used as the only basis for formulating strategies of species conservation, and corresponding field surveys should be carried out according to the simulation prediction results, so as to formulate more scientific and reasonable strategies for species conservation (Renner \& Warton, 2013; Wen et al., 2019). Correspondingly, by simulating the potential distribution area of species, it can also provide some basic and scientific evidence for species reintroduction.

\section{CONCLUSIONS}

In this study, we finally identified 25 rare, endangered and/or national protected species with high simulation accuracy, belonging to 23 genera and 19 families. The average AUC value of each species was from 0.80 to 1.00, which confirmed that the simulation precision of the MaxEnt model on each species was good or excellent. On the whole, the potential distribution area for each species was relatively concentrated, mainly distributed in the central-western, central-eastern and northern regions of Northwest Yunnan. Besides, the potential distribution areas of these species were between $826.33 \mathrm{~km}^{2}$ and $44963.53 \mathrm{~km}^{2}$. Additionally, the annual precipitation (Bio12), precipitation of coldest quarter (Bio19) and population density (Pop) had a greater contribution to the species distribution model, and their contribution values were $25.92 \%, 15.86 \%$ and $17.95 \%$, respectively. Furthermore, the goodness of fit $R^{2}$ and AIC value of the water model were 0.88 and 7703.82, respectively, which demonstrated the water factor largely influenced the potential distribution of these target species. These results would contribute to a more comprehensive understanding of the potential geographical distribution pattern of some key higher plant species in Northwest Yunnan, and would be helpful for implementing long-term conservation and reintroduction for these species.

\section{ACKNOWLEDGMENTS}

This research was supported by the "Biodiversity Survey, Observation and Assessment Program of Ministry of Ecology and Environment of the People's Republic of China". We would like to thank the respectable reviewers for their constructive suggestions.

\section{CONFLICT OF INTEREST}

The authors declare that they have no known competing financial interests or personal relationships that could have appeared to influence the work reported in this paper.

\section{AUTHOR CONTRIBUTIONS}

Jianyong $\mathrm{Wu}$ and Guangfu Zhang conceived the ideas. Jianyong $\mathrm{Wu}$ and Pengcheng Ye collected the data. Pengcheng Ye analyzed the data. Pengcheng Ye drafted the first version of the manuscript. Jianyong Wu 
and Guangfu Zhang led manuscript writing. All co-authors contributed to the scientific discussions and commented on the manuscript.

\section{DATA AVAILABILITY STATEMENT}

Detailed experimental data and results of each grid are available on Dryad. The spreadsheet contains the environment variable value, habitat suitability index (HSI) value and potential abundance of species of each grid. In addition, we also used open-access data from Worldclim version 2-Bioclimatic variables (http://worldclim.com/), Resource and Environment Data Cloud Platform (http://www.resdc.cn/Default.aspx) and National Earth System Science Data Center (http://www.geodata.cn/).

\section{ORCID}

Pengcheng Ye https://orcid.org/0000-0001-6245-3281

Jianyong Wu https://orcid.org/0000-0001-6887-3164

Guangfu Zhang https://orcid.org/0000-0001-8120-4838

\section{REFERENCES}

Convertino, M., Muñoz-carpena, R., Chu-agor, M. L., Kiker, G. A., \& Linkov, I. (2014). Untangling drivers of species distributions: Global sensitivity and uncertainty analyses of MaxEnt. Environmental Modelling \& Software, 51(51), 296-309. https://doi.org/10.1016/j.envsoft.2013.10.001.

Deb, C. R., Jamir, N. S., \& Kikon, Z. P. (2017). Distribution prediction model of a rare orchid species (Vanda bicolor Griff.) using small sample size. American Journal of Plant Sciences, 8(6), 1388-1398. https://doi.org/10.4236/ajps.2017.86094.

Esri. ArcGIS Desktop: Release 10.4. Environmental Systems Research Institute, Redlands, California, USA.

Fernandes, R. F., Honrado, J. P., Guisan, A., Roxo, A., Alves, P., Martins, J., \& Vicente, J. R. (2019). Species distribution models support the need of international cooperation towards successful management of plant invasions. Journal for Nature Conservation, 49, 85-94. https://doi.org/ 10.1016/j.jnc.2019.04.001.

Fotheringham, A. S., Charlton, M., \& Brunsdon, C. (1996). The geography of parameter space: An investigation of spatial non-stationarity. International Journal of Geographical Information Systems, 10(5), 605-627. https://doi.org/10.1080/02693799608902100.

Fotheringham, A. S., Brunsdon, C., \& Charlton, M. (2002). Geographically weighted regression: The analysis of spatially varying relationships. Wiley, Chichester.

Gao, J. B., Jiao, K. W., \& Wu, S. H. (2019). Investigating the spatially heterogeneous relationships between climate factors and NDVI in China during 1982 to 2013. Journal of Geographical Sciences, 29(10), 1597-1609. https://doi.org/10.1007/s11442-019-1682-2.

Gaston, K. J. (2000). Global patterns in biodiversity. Nature, 405(6783), 220-227. https://doi.org/10.1038/35012228.

Gong, W., Xia, Q., Chen, H. F., Yu, X. H., \& Wu, F. (2015). Prediction of potential distributions of Bretschneidera sinensis, an rare and endangered plant species in China. Journal of South China Agricultural University, 36(4), 98-104. https://doi.org/10.7671/j.issn.1001-411X.2015.04.018. 
Gouveia, S. F., Hortal, J. N., Cassemiro, F. A. S., Rangel, T. F., \& Diniz-Filho, J. A. F. (2013). Nonstationary effects of productivity, seasonality, and historical climate changes on global amphibian diversity. Ecography, 36(1), 104-113. https://doi.org/10.1111/j.1600-0587.2012.07553.x.

Guan, X. Y., Shi, W., \& Cao, K. F. (2018). Effect of climate change in future on geographical distribution of widespread Quercus acutissima and analysis of dominant climatic factors. Journal of Tropical and Subtropical Botany, 26(6), 105-112. https://doi.org/10.11926/jtsb.3898.

Han, Y., Zhu, W. B., Li, S. C. (2016). Modelling relationship between NDVI and climatic factors in China using geographically weighted regression. Acta Scientiarum Naturalium Universitatis Pekinensis, 52(6), 11251133. https://doi.org/10.13209/j.0479-8023.2015.130.

Hernandez, P. A., Graham, C. H., Master, L. L., \& Albert, D. L. (2006). The effect of sample size and species characteristics on performance of different species distribution modeling methods. Ecography, 29(5), 773-785. https://doi.org/10.1111/j.0906-7590.2006.04700.x.

Huang, Z. H., Zhou, X., Zhang, X. R., Pu, Z., \& Xing, S. H. (2018). Suitability assessments of potential distribution areas for Amur corktree in mainland China. Acta Ecologica Sinica, 38(20), 7469-7476. https://doi.org/10.5846/ stxb201711071997.

Hall, L. S., Krausman, P. R., \& Morrison, M. L. (1997). The habitat concept and a plea for standard terminology. Wildlife Society Bulletin, 25(1), 173-182. https://doi.org/10.2307/3783301.

Lazo-Cancino, D., Rivera, R., Paulsen-Cortez, K., González-Berríos, N., Rodríguez-Gutiérrez, R., \& Rodríguez-Serrano, E. (2020). The impacts of climate change on the habitat distribution of the vulnerable Patagonian-Fueguian species Ctenomys magellanicus (Rodentia, Ctenomyidae). Journal of Arid Environments, 173, 104016. https://doi.org/10.1016/j.jaridenv.2019.104016.

Li, C., Zhao, J., \& Xu, Y. (2017). Examining spatiotemporally varying effects of urban expansion and the underlying driving factors. Sustainable Cities and Society, 28, 307-320. https://doi.org/10.1016/j.scs.2016.10.005.

Li, J. J, Fan, G., \& He, Y. (2020). Predicting the current and future distribution of three Coptis herbs in China under climate change conditions, using the MaxEnt model and chemical analysis. Science of the Total Environment, 698, 134141. https://doi.org/10.1016/j.scitotenv.2019.134141.

Liu, S. L., Dong, Y. H., \& Sun, Y. (2019). Modelling the spatial pattern of biodiversity utilizing the highresolution tree cover data at large scale: Case study in Yunnan Province, Southwest China. Ecological Engineering, 134, 1-8. https://doi.org/10.1016/j.ecoleng.2019.05.001.

Lu, B. B., Ge, Y., Qin, K., \& Zheng, J. H. (2020). A summary on geographically weighted regression. Geomatics and Information Science of Wuhan University, 45(9), 1356-1366. https://doi.org/10.13203/j.whugis20190346.

Myers, N., Mittermeier, R. A., Mittermeier, C. G., Fonseca, G. A. B., \& Kent, J. (2000). Biodiversity hotspots for conservation priorities. Nature, 403(6772), 853-858. https://doi.org/10.1038/35002501.

McCord, M. J., Macintyre, S., Bidanset, P., Lo, D., \& Davis, P. (2018). Examining the spatial relationship between environmental health factors and house prices. Journal of European Real Estate Research, 11(3), 353-398. https://doi.org/10.1108/JERER-01-2018-0008.

Merow, C., Smith, M. J., \& Silander, J. A., 2013. A practical guide to MaxEnt for modeling species' distributions: What it does, and why inputs and settings matter. Ecography, 36(10), 1058-1069. https://doi.org/10.1111/j.1600-0587.2013.07872.x.

Mukherjee, T., Sharma, L. K., Saha, G. K., Thakur, M., \& Chandra, K. (2020). Past, Present and Future: Combining habitat suitability and future landcover simulation for long-term conservation management of Indian rhino. Scientific Reports, 10(1), 606. https://doi.org/10.1038/s41598-020-57547-0. 
Nieto, S., Flombaum, P., \& Garbulsky, M. F. (2015). Can temporal and spatial NDVI predict regional birdspecies richness? Global Ecology and Conservation, 3, 729-735. https://doi.org/10.1016/j.gecco.2015.03.005.

Ning, Y., Lei, J. R., Song, X. Q., Han, S. M., \& Zhong, Y. F. (2020). Modeling the potential suitable habitat of Impatiens hainanensis, a limestone-endemic plant. Chinese Journal of Plant Ecology, 42(9), 946-954. https://doi.org/10.17521/cjpe.2018.0066.

Phillips, S. J., Dudik, M., \& Schapire, R. E. (2004). A maximum entropy approach to species distribution modeling. In: Proceedings of the Twenty-First International Conference on Machine Learning (pp. 472-486). New York: ACM Press. https://doi.org/10.1145/1015330.1015412.

Phillips, S. J., Anderson, R. P., \& Schapire, R. E. (2006). Maximum entropy modeling of species geographic distributions. Ecological Modelling, 190(3), 231-259. https://doi.org/10.1016/j.ecolmodel.2005.03.026.

Phillips, S. J., \& Dudík, M., (2008). Modeling of species distributions with Maxent: New extensions and a comprehensive evaluation. Ecography, 31(2), 161-175. https://doi.org/10.1111/j.0906-7590.2008.5203.x.

Renner, I. W., \& Warton, D. I. (2013). Equivalence of MaxEnt and poisson point process models for species distribution modeling in ecology. Biometrics, 69(1), 274-281. https://doi.org/10.1111/j. 15410420.2012.01824.x.

Ștefănescu, D. M., Răduțoiu, D., \& Marinescu, E. (2017). The importance of climate, productivity, habitat heterogeneity, and human impact on the distribution of bird of prey species richness across two continents latitudinal gradient (Europe and Africa). North-Western Journal of Zoology, 13(2), 285-296. Available online, http://biozoojournals.ro/nwjz/content/v13n2/nwjz_e161608_Stefanescu.pdf (Accessed date: 10 September 2020).

Tao, G. Q., Ou, X. K., Guo, Y. M., Xu, Q., Yu, Q. C., Zhang. Z. M., \& Wang, C. Y. (2016). Priority area identification for vegetation in Northwest Yunnan, based on protection value and protection cost. Acta Ecologica Sinica, 36(18), 5777-5789. https://doi.org/10.5846/stxb201504040677.

Tobler, W. R. (1970). A computer movie simulating urban growth in the Detroit region. Economic Geography, 46(2), 234-240. https://doi.org/10.2307/143141.

Tripathi, P., Behera, M. D., \& Roy, P. S. (2019a). Spatial heterogeneity of climate explains plant richness distribution at the regional scale in India. PLoS One, 14(6), e0218322. https://doi.org/10.1371/journal.pone.0218322.

Tripathi, P., Behera, M. D., \& Roy, P. S. (2019b). Plant invasion correlation with climate anomaly: An Indian retrospect. Biodiversity and Conservation, 28(8), 2049-2062. https://doi.org/10.1007/s10531-019-01711-0.

Wang, B., Huang, Y., Li, J. T., Dai, Q., Wang, Y. Z., \& Yang, D. D. (2018). Amphibian species richness patterns in karst regions in Southwest China and its environmental associations. Biodiversity Science, 26(9), 27-36. https://doi.org/10.17520/biods.2018125.

Wang, C., Wang, G., Guo, Z. R., Dai, L. J., Liu, H. Y., Li, Y. F., Chen, H., Zhao, Y. X., Zhang, Y. N., \& Cheng, H. (2020). Effects of land-use change on the distribution of the wintering red-crowned crane (Grus japonensis ) in the coastal area of Northern Jiangsu Province, China. Land Use Policy, 90, 104269. https://doi.org/10.1016/j.landusepol.2019.104269.

Wang, L. M., Bu, X. L., Luo, T., Huang, D. F., \& Chen, Q. B. (2013). Soil erosion dynamics and its influencing factors in eco-restoration of plateau region in Northwest of Yunnan Province, China. Ecology and Environmental Sciences, 22(9), 1550-1555. https://doi.org/10.3969/j.issn.1674-5906.2013.09.015.

Wen, X. M., Muhtar, A., Abduxuker, M., \& Abbas, A. (2019). Habitat suitability assessment of lichen genus Acarospora in Xinjiang based on MaxEnt model. Journal of Wuhan University (Natural Science Edition), 65(2), 77-84. https://doi.org/10.14188/j.1671-8836.2019.01.010. 
Wu, J. Y., Xue, D. Y., Wang, A. H., \& Zhao, F. W. (2016). Case studies on the identification of key biodiversity areas (KBAs) in foreign countries and progress and prospects in China. Acta Ecologica Sinica, 36(10), 3108-3114. https://doi.org/10.5846/stxb201408261695.

Xiao, J., Xu, W. H., Kang, D. W., \& Li, J. Q. (2011). Nature reserve group planning for conservation of giant pandas in North Minshan, China. Journal for Nature Conservation, 19(4), 209-214. https://doi.org/10.1016/j.jnc.2011.01.003.

Xu, C. C., Zhao, J. Y., \& Liu, P. (2019). A geographically weighted regression approach to investigate the effects of traffic conditions and road characteristics on air pollutant emissions. Journal of Cleaner Production, 239, 118084. https://doi.org/10.1016/j.jclepro.2019.118084.

Xu, H. G., Cao, M. C., Wu, J., Cai, L., Ding, H., Lei J. C., Wu, Y., Cui, P., Chen, L., Le, Z. F., \& Cao, Y. (2015). Determinants of mammal and bird species richness in China based on habitat groups. PLoS One, 10(12), e0143996. https://doi.org/10.1371/journal.pone.0143996.

Xu, J., Cao, B., \& Bai, C. K. (2015). Prediction of potential suitable distribution of endangered plant Kingdonia uniflora in China with MaxEnt. Chinese Journal of Ecology, 34(12), 3354-3359. https://doi.org/10.13292/j.1000-4890.2015.0307.

Xue, D. Y., \& Wu, J. Y. (2016). Biodiversity and conservation in the upper and middle reaches of the Yangtze River-A report from the Northwest of Yunnan Province. Environmental Protection, 44(15), 31-35. https://doi.org/10.14026/j.cnki.0253-9705.2016.15.005.

Xue, R. H., Yu, X. P., Li, D. Q., \& Ye, X. P. (2020). Using geographically weighted regression to explore the effects of environmental heterogeneity on the space use by giant pandas in Qinling Mountains. Acta Ecologica Sinica, 40(8), 2647-2654. https://doi.org/10.5846/stxb201903120469.

Yang, C. R., Zhao, K. R., Lv, S. T., \& Shu, Q. T. (2013). Study on forest fire risk zone mapping for ShangriLa based on RS and GIS. Forest Resources Management, (1), 102-107. https://doi.org/10.3969/j.issn.10026622.2013.01.021.

Yang, J. W. (2002). Status and solutions of biodiversity protection in Northwest Yunnan. Forest Resources Management, (3), 61-65. https://doi.org/10.3969/j.issn.1002-6622.2002.03.016.

Yang, Y. M., Wang, J., \& Li, H. M. (2017). Study on biodiversity conservation strategy and action plan in Yunnan Province. Beijing: Science Press.

Ye, P. C., Zhang, G. F., \& Wu, J. Y. (2020a). Hotspots and conservation gaps: A case study of key higher plant species from Northwest Yunnan, China. Global Ecology and Conservation, e01005. https://doi.org/10.1016/j.gecco.2020.e01005.

Ye, P. C., Chen, H., Wu, J. Y., \& Zhang, G. F. (2020b). Distribution pattern and correlation with main environmental factors of higher plant diversity in Northwest Yunnan. Journal of Ecology and Rural Environment, 36(1), 89-94. https://doi.org/10.19741/j.issn.1673-4831.2019.0142.

Yi, Y. J., Zhou, Y., Cai, Y. P., Yang, W., Li, Z. W., \& Zhao, X. (2017). The influence of climate change on an endangered riparian plant species: The root of riparian Homonoia. Ecological Indicators, 92, 40-50. https://doi.org/10.1016/j.ecolind.2017.05.004.

Yu, S. X., Liu, Y., Jiang, H., Deng, C. Y., \& Qin, H. N. (2014). Important plant resources of karst area in Guangxi, Yunnan and Guizhou. Beijing: Science Press.

Zhang, H. X., Zhang, M. L., \& Wang, Y. (2017). Distribution pattern of poisonous plant species in arid grasslands: A case from Xinjiang, Northwestern China. The Rangeland Journal, 39(3), 279-287. https://doi.org/10.1071/RJ16018.

Zhang, J. J., Jiang, F., Li, G. Y., Qin, W., Li, S. Q., Gao, H. M., Cai, Z. Y., Lin, G. H., \& Zhang, T. Z. (2019). Maxent modeling for predicting the spatial distribution of three raptors in the Sanjiangyuan 
National Park, China. Ecology and Evolution, 9(11), 6643-6654. https://doi.org/10.1002/ece3.5243.

Zhang, M. G., Zhou, Z. K, Chen, W. Y., Slik, J. W. F., Cannon, C. H., \& Raes, N. (2012). Using species distribution modeling to improve conservation and land use planning of Yunnan, China. Biological Conservation, 153, 257-264. https://doi.org/10.1016/j.biocon.2012.04.023.

Zhang, Y., Li, J., Lin, W., \& Qiang, S. (2011). Prediction of potential distribution area of Erigeron philadelphicus in China based on MaxEnt model. Chinese Journal of Applied Ecology, 22(11), 2970-2976. https://doi.org/10.3969/j.issn.1009-6663.2013.08.061.

Zhang, Y. B., \& Ma, K. P. (2008). Geographic distribution patterns and status assessment of threatened plants in China. Biodiversity and Conservation, 17(7), 1783-1798. https://doi.org/10.1007/s10531-008-93846 .

Zhang, Y. B., Liu, Y. L., Fu, J. X., Phillips, N., Zhang, M. G., \& Zhang, F. (2016). Bridging the "gap" in systematic conservation planning. Journal for Nature Conservation, 31, 43-50. https://doi.org/10.1016/j.jnc.2016.03.003.

Zhu, G. P., Yuan, X. J., Fan, J. Y., \& Wang, M. L. (2018). Effects of model parameters in MaxEnt modeling of ecological niche and geographic distribution: Case study of the brown marmorated stink bug, Halyomorpha haly. Journal of Biosafety, 27(2), 46-51. https://doi.org/ 10.3969/j.issn.2095-1787.2018.02.007.

Zhuang, H. F., Qin, H., Wang, W., \& Zhang, Y. B. (2018a). Prediction of the potential suitable distribution of Taxus yunnanensis based on MaxEnt model. Journal of Shanxi University (Natural Science Edition), 41(1), 233-240. https://doi.org/10.13451/j.cnki.shanxi.univ(nat.sci.).2018.01.030.

Zhuang, H. F., Zhang, Y. B., Wang, W., Ren, Y. H., Liu, F. Z., Du, J. H., \& Zhou, Y. (2018b). Optimized hot spot analysis for probability of species distribution under different spatial scales based on MaxEnt model: Manglietia insignis case. Biodiversity Science, 26(9), 931-940. https://doi.org/10.17520/biods.2018059.

\section{SUPPORTING INFORMATION}

Additional supporting information may be found online in the Supporting Information section at the end of the article.

\section{Hosted file}

Figure.rar available at https://authorea.com/users/381604/articles/497509-potentialgeographical-distribution-and-environmental-explanations-of-rare-and-endangered-plant-

species-through-combined-modelling-a-case-study-of-northwest-yunnan-china 